\title{
Desenvolvimento inicial de olerícolas cultivadas em solos contaminados com resíduos de 2,4-d + picloram
}

\author{
Initial development of vegetable crops cultivated \\ in soils with 2,4-d + picloram resídues
}

\author{
Elton Rocha do Nascimento ${ }^{1}$; Oscar Mitsuo Yamashita ${ }^{2 *}$
}

\begin{abstract}
Resumo
A olericultura sempre teve papel importante na produção de alimentos no Brasil. Essa atividade tem um forte aspecto social, pois as atividades realizadas para seu cultivo necessitam de mão-deobra em todas as fases do processo produtivo. Com o aumento da produção de olerícolas, surgiram fatores que influenciaram negativamente no seu cultivo, como o aparecimento de pragas e doenças e a contaminação do substrato com resíduos sólidos e líquidos. O presente trabalho teve como objetivo avaliar o comportamento de olerícolas (pepino, alface e tomate) cultivadas em solos com aplicação da formulação de herbicida 2,4-D + Picloram nas subdoses de 0,04;0,08;0,24;0,48 e 0,96 L ha ${ }^{-1}$ e comparadas com a testemunha (solo sem contaminar). O delineamento experimental adotado foi o inteiramente casualizado. Avaliou-se a emergência de plântulas, a altura destas e a fitointoxicação promovida pelo cultivo em solo previamente contaminado. Concluiu-se que solos contaminados com 2,4-D + Picloram provocaram redução na emergência e altura das plantas e o aumento na fitotoxicidade em doses acima de $0,04 \mathrm{~L} \mathrm{ha}^{-1}$.
\end{abstract}

Palavras-chave: Herbicida, alface, tomate, pepino

\begin{abstract}
Vegetable crops have an important role in the production of foods in Brazil. This activity is important also due to the social aspect, because the need of labor in all of the phases of the productive process. With the increase of vegetable crops production, factors that influenced negatively in the cultivation appeared, like the emergence of curses and diseases and the contamination of the substratum with solid and liquid residues. The present research work had the aim of evaluating vegetable crops (cucumber, lettuce and tomato) performance when cultivated in soils with application of formulation of 2,4-D + Picloram herbicide in subdoses of $0.04 ; 0.08 ; 0.24 ; 0.48$ and $0.96 \mathrm{~L} \mathrm{ha}^{-1}$ and compared with the control (without contaminating), in a completely randomized design. The evaluations were emergency, intoxication and height of plants. Soils with 2,4-D + Picloram caused reduction in the emergency and in the height of plants. The increase in the phytointoxication occurred in doses above $0.04 \mathrm{~L} \mathrm{ha}^{-1}$.
\end{abstract}

Key words: Herbicide, cucumber, lettuce, tomato

\footnotetext{
${ }^{1}$ Eng. Agrônomo. Esp. BRASTERRA Consultoria e Planejamento Agroflorestal. Alta Floresta-MT. E:mail: eltonrn@hotmail. com

2 Eng. Agrônomo. MSc. Prof. Dep. Agronomia da UNEMAT. Doutorando em Agricultura Tropical pela FAMEV/UFMT. E:mail: yama@unemat.br

* Autor para correspondência
} 


\section{Introdução}

A característica geral e marcante do agronegócio da produção de olerícolas é o fato de ser uma atividade agroeconômica altamente intensiva, em seus mais variados aspectos, em contraste com outras atividades, extensivas, como a produção de grãos. Desse modo, há o emprego contínuo do solo em uma área, com vários ciclos culturais (FILGUEIRA, 2003).

O solo é o substrato natural para a produção agrícola, servindo como local para o desenvolvimento das raízes, a sustentação do vegetal, além de ser o meio no qual a planta retira os nutrientes para seu pleno desenvolvimento (WEBBER; MILLER, 1989).

Resíduos de herbicidas no solo tem sido descritos pela literatura como responsáveis por reduções na produtividade de culturas sucessoras (JOHNSON; LAVY; GBUR, 1995; ALENCAR et al., 1998; ALVARENGA et al., 2003; THILL, 2003). Alguns desses produtos como triclopyr e picloram apresentam período residual longo, podendo gerar problemas para o desenvolvimento de espécies sensíveis (CESSNA; WADDINGTON; BITTMAN, 1986; ROMAN et al., 2007), principalmente quando se utiliza a matéria orgânica proveniente de áreas tratadas com esses herbicidas (SANTOS et al., 2006).

O pepino é utilizado como planta indicadora de contaminação de substrato com herbicidas auxínicos (THILL, 2003). Entretanto, essa e outras espécies como pimentão, tomate, alface, videira e fumo podem ser cultivadas para fins comerciais e sofrer a ação fitotóxica da presença de resíduos de herbicidas como picloram, fluroxypir e triclopyr presentes em substrato contaminado(DEUBERT; CORTE-REAL, 1986; OLIVEIRA JÚNIOR et al., 2007; SILVA; FERREIRA; FERREIRA, 2007), podendo provocar desde o crescimento anormal das plantas, gerando perdas na produtividade, até a morte das plantas intoxicadas (MULLAHEY; CORNELL; COLVIN, 1993; MISLEVY; MULLAHEY; MARTIN, 1997; FREITAS et al., 2003).
Os sintomas de intoxicação pelos herbicidas auxínicospodemvariardeacordocomaconcentração. Esses compostos provocam intensa divisão celular, promovendo a formação de anomalias como tumores e engrossamento do caule e raízes. Ocorre a formação de gemas múltiplas e hipertrofia das raízes laterais e um dos mais conhecidos sintomas é o crescimento desorganizado e a epinastia das folhas e retorcimento do caule (SILVA; FERREIRA; FERREIRA, 2002; DEUBER, 2003; ROMAN et al., 2007).

Diante da crescente utilização de herbicidas na agricultura e do risco de contaminação da biota no ambiente, o presente trabalho teve como objetivo avaliar e verificar o comportamento de pepino, alface e tomate cultivados em solos contaminados com subdoses do herbicida 2,4-D + Picloram.

\section{Material e Métodos}

Opresente trabalho foi desenvolvidonomunicípio de Alta Floresta, localizado no extremo norte do Estado de Mato Grosso, situado nas coordenadas 09 52 ' $18^{\prime \prime}$ de latitude Sul e $56^{\circ} 06^{\prime} 41^{\prime \prime}$ de longitude Oeste. Encontra-se a $350 \mathrm{~m}$ acima do nível do mar. O clima é do tipo Awi, segundo a classificação Köppen, tropical chuvoso com nítida estação seca. A temperatura varia entre $20^{\circ}$ e $38^{\circ} \mathrm{C}$, com média de $26^{\circ} \mathrm{C}$. A precipitação pluviométrica encontra-se em torno de $2400 \mathrm{~mm} / \mathrm{ano}$, com umidade relativa média anual de 70\% (BRASIL, 1980).

O trabalho foi realizado em viveiro pertencente à Comissão Executiva do Plano da Lavoura Cacaueira (CEPLAC), equipada com sistema de nebulização intermitente, cujo intervalo era controlado por mecanismo automático.

Para a realização do experimento, utilizouse solo retirado de área livre de contaminação de herbicida, eliminando-se os primeiros cinco centímetros superficiais. O solo foi contaminado com subdoses do herbicida Tordon ${ }^{\circledR}$, que apresenta na sua formulação 2,4-D + Picloram (240 g e.a. 
ha $^{-1}+64$ g e.a. ha ${ }^{-1}$, respectivamente). Para isso, calculou-se um volume de solo correspondente a 1,0 ha a $20 \mathrm{~cm}$ de profundidade. Esse volume foi contaminado com cinco concentrações reduzidas em relação à recomendação do herbicida $\left(4,0 \mathrm{~L} \mathrm{ha}^{-1}\right)$ para controle de plantas daninhas em pastagens. As diferentes dosagens utilizadas foram: $25 \%$ da dose $\left(0,96 \mathrm{~L} \mathrm{ha}^{-1}\right) ; 12 \%\left(0,48 \mathrm{~L} \mathrm{ha}^{-1}\right) ; 6 \%\left(0,24 \mathrm{~L} \mathrm{ha}^{-1}\right)$; $2 \%\left(0,08 \mathrm{~L} \mathrm{ha}^{-1}\right)$ e $1 \%\left(0,04 \mathrm{~L} \mathrm{ha}^{-1}\right)$, além de solo sem contaminação (testemunha).

Forampreparadassoluçõescorrespondentesacada dose, através da diluição do produto comercial em água destilada (calda do herbicida). Posteriormente, foram retiradas doses de herbicida com auxílio de pipetador automático e, em recipientes livres de resíduos, o solo recebeu o herbicida, sendo misturado vigorosamente até a homogeneização completa. No momento da contaminação, o solo apresentava-se ligeiramente úmido. Cada unidade experimental foi representada por um vaso plástico de capacidade para $0,5 \mathrm{~L}$, preenchido com o substrato.

Em cada vaso, foram semeadas 20 sementes de três espécies olerícolas: alface, pepino e tomate. As sementes foram previamente submetidas a teste padrão de germinação (BRASIL, 1992), cuja media foi superior a $95 \%$.

A semeadura foi realizada a $1,0 \mathrm{~cm}$ de profundidade. $\mathrm{O}$ reumedecimento do substrato, através de sistema de nebulização intermitente, mantendo-se a umidade do substrato próximo a $80 \%$ da capacidade de campo.
O delineamento experimental adotado foi o DIC (delineamento inteiramente casualizado) com quatro repetições.

Para a fitointoxicação das plantas, foram realizadas avaliações visuais aos 7, 11 e 14 dias após a semeadura, por meio de notas, em escala que variaram de 0 a 10 (adaptada de SOCIEDADE BRASILEIRA DA CIÊNCIA DAS PLANTAS DANINHAS - SBCPD, 1995), onde 0 era a ausência de qualquer sintoma de fitotoxicidade e 10 caracterizava a morte da planta (Tabela 1).

A altura das plantas foi tomada aos 14 dias após a semeadura, medindo-se aleatoriamente 10 plantas dentro de cada vaso, da região do colo da planta até a gema terminal da haste principal.

A contagem de emergência de plântulas foi realizada diariamente, a partir dos cinco dias da semeadura, contando-se plântulas que haviam emitido caulículo acima da superfície do substrato.As avaliações encerraram-se aos 14 dias da semeadura. Com base nos dados, foram confeccionadas tabelas com a emergência acumulada aos cinco e 14 dias da semeadura.

Os dados coletados foram submetidos á analise de variância (teste F), comparando-se as médias pelo teste de Scott \& Knott a 5\% de probabilidade. As variáveis emergência e altura de planta foram submetidas à análise de regressão, buscando apresentar explicação matemática para o fenômeno.

Tabela 1. Escala de notas utilizada para avaliação visual de fitotoxicidade do herbicida 2,4-D + Picloram em diferentes olerícolas. Alta Floresta, MT, 2007.

\begin{tabular}{|c|c|c|}
\hline CONCEITO & NOTAS & OBSERVAÇÕES \\
\hline Leve & $0-1$ & $\begin{array}{l}\text { Sintomas fracos ou poucos evidentes. Nota zero: não se observam quaisquer } \\
\text { alterações nas plantas }\end{array}$ \\
\hline Aceitável & $2-3$ & Sintomas pronunciados, no entanto totalmente tolerados pela planta \\
\hline Preocupante & $4-5$ & $\begin{array}{l}\text { Sintomas maiores que na categoria anterior, mas ainda passíveis de recuperação, e } \\
\text { sem expectativas de redução no rendimento econômico. }\end{array}$ \\
\hline Alta & $5-7$ & Danos irreversíveis, com previsão de redução no rendimento econômico. \\
\hline Muito alta & $7-10$ & $\begin{array}{l}\text { Danos irreversíveis muito severos, com previsão de redução drástica no rendimento } \\
\text { econômico. Nota } 10 \text { para morte da planta. }\end{array}$ \\
\hline
\end{tabular}

Adaptado SBCPD (1995). 


\section{Resultados e Discussão}

Para a variável emergência de plântulas, houve efeito significativo para espécies $(p<0,01)$, para doses $(\mathrm{p}<0,01)$ e para a interação entre espécies e doses $(\mathrm{p}<0,05)$.

Confeccionando-se gráfico de regressão com os dados acumulados aos 14 dias da semeadura, observou-se que todas as espécies estudadas apresentaram redução linear à medida que as doses eram aumentadas (Figura 1).

Quando as culturas foram semeadas em substrato sem o herbicida, não houve diferença de emergência entre as espécies, apresentando percentual superior a 95\% (Tabela 2). Observou-se que, nas doses de 0,$04 ; 0,08$ e $0,24 \mathrm{~L} \mathrm{ha}^{-1}$, as plantas de alface e pepino apresentavam emergência significativamente superior às de tomate. Alface apresentou emergência 16,5 e $10,5 \%$ superior a tomate e pepino quando o solo foi contaminado com $0,48 \mathrm{~L} \mathrm{ha}^{-1}$ da dose do herbicida. A partir dessa dose, as plantas de todas as espécies se mostraram extremamente sensíveis à contaminação do herbicida, apresentando emergência inferior a $65 \%$. Resultados semelhantes foram observados por Santos et al. (2006), em pepino, usando 1,5 $\mathrm{L} \mathrm{ha}^{-1}$. Já quando o solo recebeu $25 \%$ da dose do herbicida $\left(0,96 \mathrm{~L} \mathrm{ha}^{-1}\right)$, maior percentual de emergência de plântulas $(65 \%)$ foi observado no pepino, sendo significativamente maior que alface e tomate.

Com relação à altura de planta, observou-se que houve efeito significativo para dose $(p<0,01)$ na avaliação realizada aos 14 dias após a semeadura (DAS).

Para todas as olerícolas estudadas, observouse que a aplicação da menor dose $\left(0,04 \mathrm{~L} \mathrm{ha}^{-1}\right)$ já provocou redução na altura de plantas em relação à testemunha. As maiores diferenças foram observadas em pepino e tomate, cuja redução entre plantas cultivadas em substrato não tratado e em substrato com $1 \%$ de contaminação $\left(0,04 \mathrm{~L} \mathrm{ha}^{-1}\right)$ foi de 33 e $30 \%$, respectivamente. E, a medida que as doses eram aumentadas, essa diferença tornou-se cada vez maior (Figura 2).

Esses resultados demonstram a alta sensibilidade dessas espécies (pepino e tomate) aos herbicidas auxínicos, levando a mudanças no seu metabolismo vegetal. Os compostos auxínicos como 2,4-D e picloram, atuam sobre o crescimento da planta, desorganizando-o. O efeito desses herbicidas podem ser observados pelo crescimento anormal de certas partes, como vasos do floema e os tecidos adjacentes, causando epinastia (DEUBER, 2003). Apesar de observada redução na altura de plantas de alface, quando cultivado em solo contaminado, esta não foi tão drástica como as outras espécies estudadas.

Tabela 2. Emergência de olerícolas, após 14 dias da semeadura em substrato contaminado com 2,4-D + Picloram. Alta Floresta-MT, 2007.

\begin{tabular}{lcccccc}
\hline \multirow{2}{*}{ Espécie } & \multicolumn{7}{c}{ Subdoses de 2,4-D + Picloram $\left(\mathbf{L ~ h a}^{\mathbf{- 1}}\right)$} \\
\cline { 2 - 7 } & $\mathbf{0 , 0 0}$ & $\mathbf{0 , 0 4}$ & $\mathbf{0 , 0 8}$ & $\mathbf{0 , 2 4}$ & $\mathbf{0 , 4 8}$ & $\mathbf{0 , 9 6}$ \\
\hline Alface & $96,3 \mathrm{Aa}$ & $97,5 \mathrm{Aa}$ & $88,7 \mathrm{Ab}$ & $82,5 \mathrm{Ab}$ & $83,8 \mathrm{Ab}$ & $53,8 \mathrm{Bc}$ \\
Tomate & $95,0 \mathrm{Aa}$ & $87,5 \mathrm{Ba}$ & $77,5 \mathrm{Bb}$ & $71,3 \mathrm{Bb}$ & $70,0 \mathrm{Bb}$ & $58,8 \mathrm{Bc}$ \\
Pepino & $96,3 \mathrm{Aa}$ & $95,0 \mathrm{Aa}$ & $85,0 \mathrm{Ab}$ & $88,8 \mathrm{Ab}$ & $75,0 \mathrm{Bc}$ & $65,0 \mathrm{Ad}$ \\
\hline C.V. (\%) & 7,23 & \multicolumn{7}{c}{} \\
\hline
\end{tabular}

Médias seguidas de mesma letra maiúscula nas colunas e minúscula nas linhas não diferem entre si pelo teste de Scott \& Knott a $5 \%$ de probabilidade. 


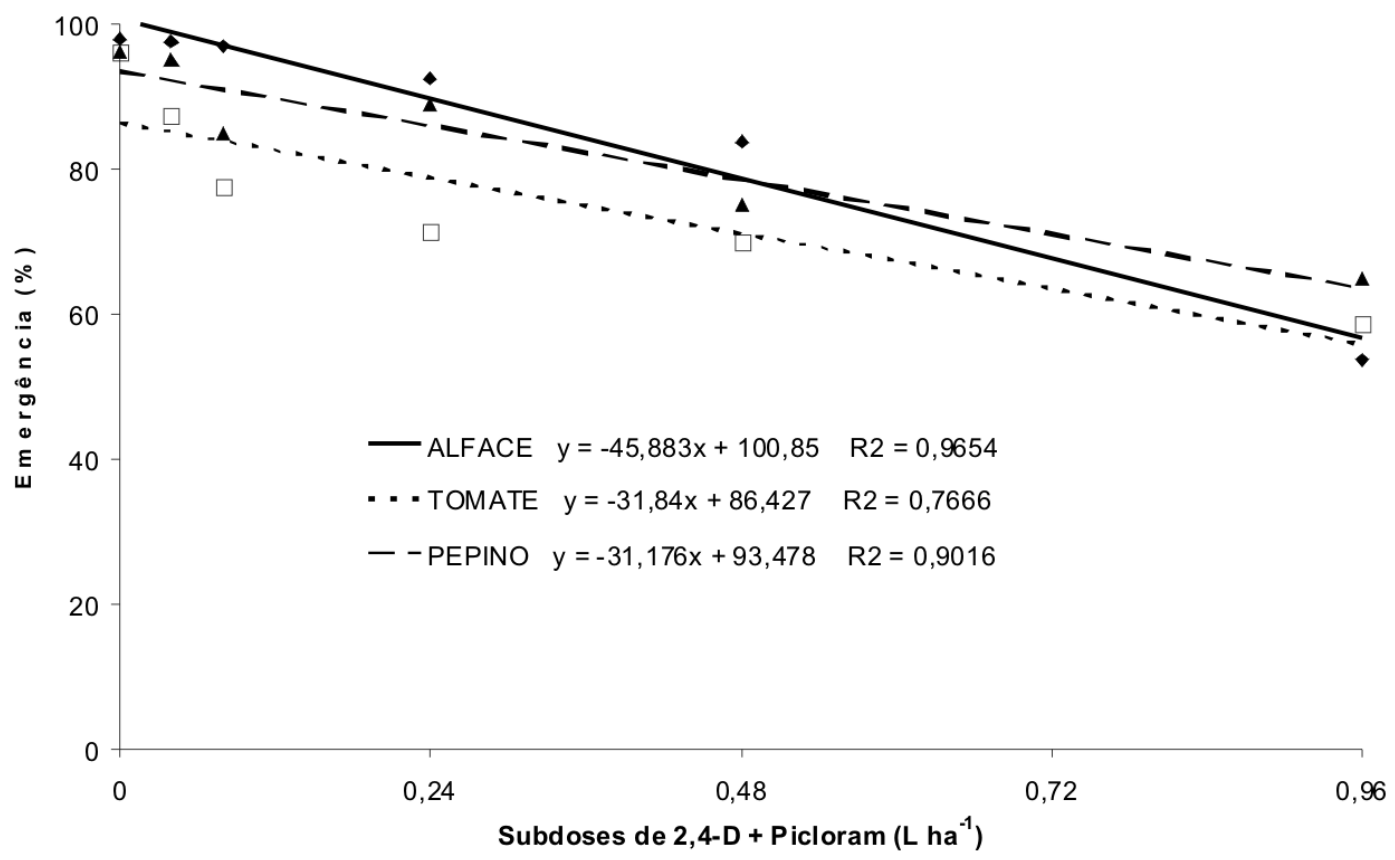

Figura 1. Emergência de plantas de alface, tomate e pepino, após 14 dias da semeadura em substrato contaminado com 2,4-D + Picloram. Alta Floresta-MT, 2007.

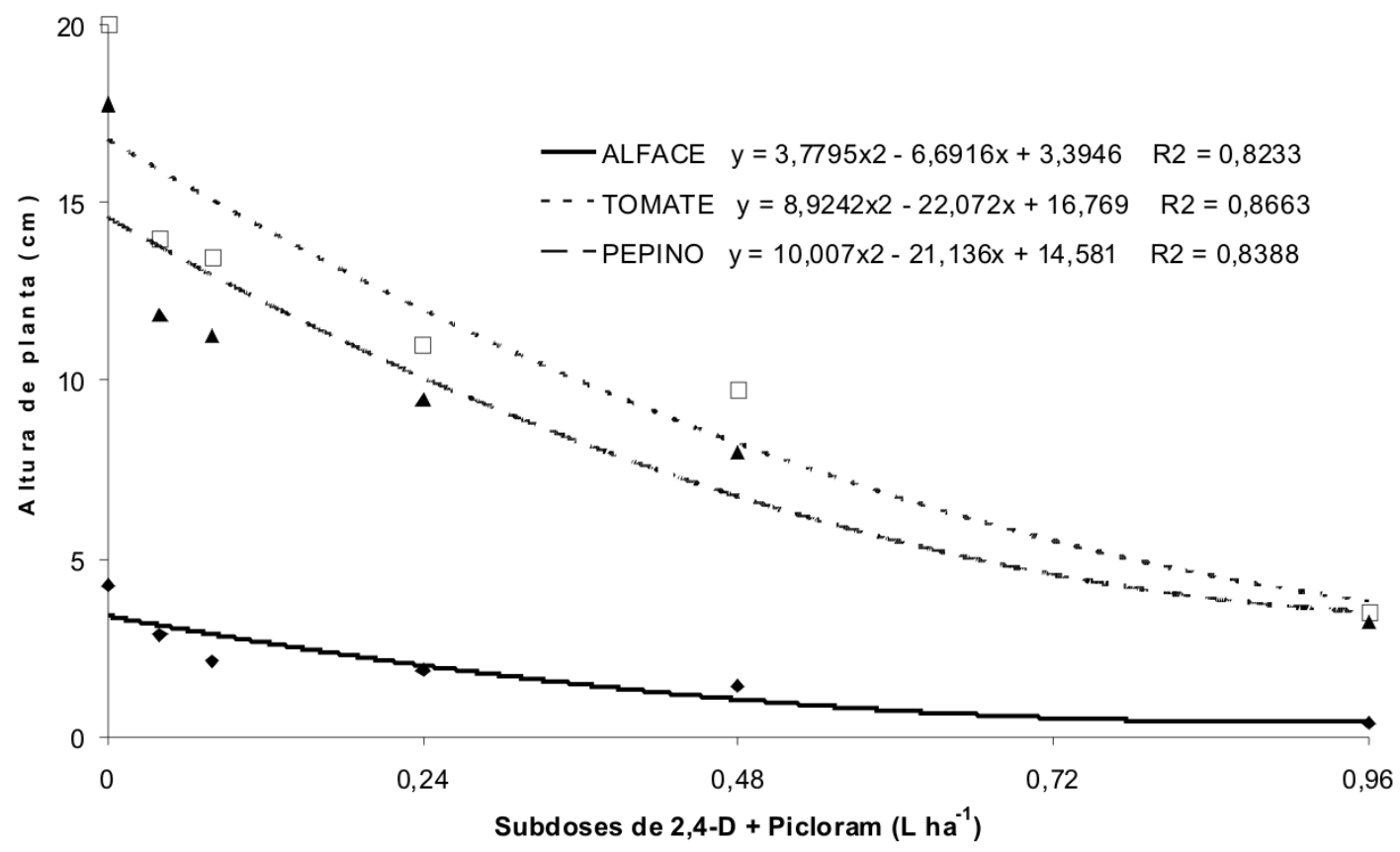

Figura 2. Altura de plantas de alface, tomate e pepino, após 14 dias da semeadura em substrato contaminado com 2,4-D + Picloram. Alta Floresta-MT, 2007. 
Quanto a fitointoxicação, observou-se que todas as espécies que foram semeadas em substrato contaminado com 2,4-D + Picloram manifestaram sintomas visuais nas folhas. Esses sintomas começaram a ser observados nitidamente após 4 dias da semeadura, onde as plântulas cresceram de forma anormal em relação á testemunha, havendo retorcimento do caule, principalmente do tomate, nas maiores concentrações do herbicida. Além disso, foi observado amarelecimento gradativo das folhas das plantas, principalmente de alface em solo contaminado com a maior concentração do herbicida, a partir dos 7 DAS.

Aos 14 DAS, os sintomas de fitotointoxicação apresentados pelas culturas foram classificados como leves a aceitáveis quando cultivados em solos contaminados com doses de 0,04 e 0,08 $\mathrm{L} \mathrm{ha}^{-1}$ (Figura 3 e Tabela 3). Maiores notas foram observadas na dose de $0,96 \mathrm{~L} \mathrm{ha}^{-1}$ para todas as espécies avaliadas, sendo classificadas como altas e muito altas, com perspectiva de provocar danos irreversíveis no desenvolvimento das plantas e conseqüentemente a possibilidade de redução no rendimento econômico. Alguns trabalhos relatam a forte fitointoxicação de 2,4-D em diversas culturas, mesmo em reduzidas concentrações (FAGLIARI et al., 2004; CONSTANTIN et al., 2007; OLIVEIRA JÚNIOR et al., 2007). Os resultados do presente trabalho mostram que alface, pepino e tomate cultivados em substrato contaminado com 2,4-D + Picloram são sensivelmente afetadas pelo herbicida.

Comparando-se as avaliações realizadas aos $7 \mathrm{e}$ 14 DAS, observou-se que para alface, as notas de fitointoxicação aumentaram proporcionalmente às doses e às datas de avaliação. Para tomate e pepino, observou-se que, apesar de haver sintomas de fitointoxicação significativamente superiores à da testemunha, não houve diferença entre as doses de 0,04 e $0,08 \mathrm{~L} \mathrm{ha}^{-1}$. Esses dados concordam com os encontrados por Santos et al. (2004), que observaram sensibilidade do pepino a doses crescentes de herbicidas derivados de auxinas sintéticas, como o 2,4-D.

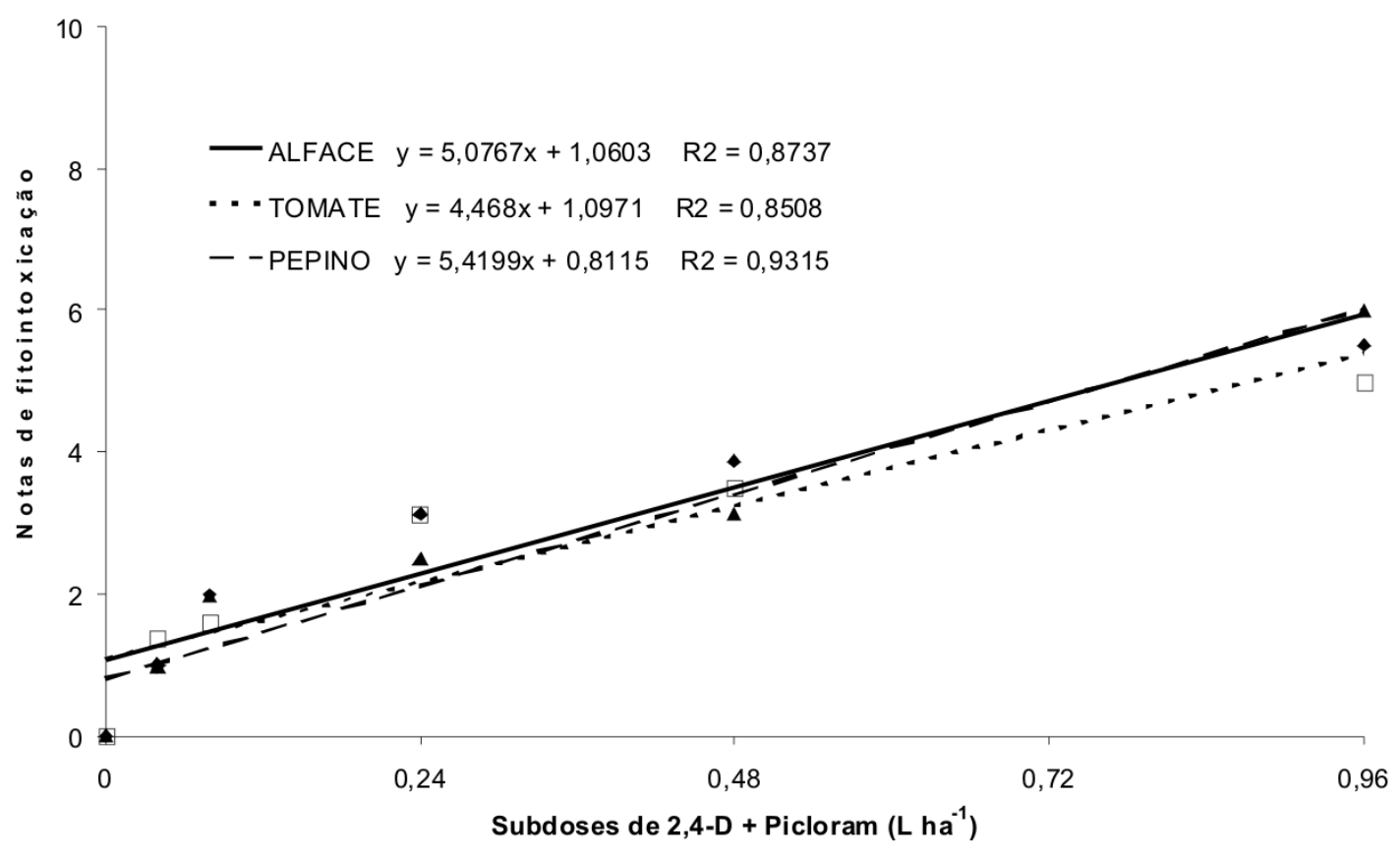

Figura 3. Fitotointoxicação de plantas de alface, tomate e pepino, após 14 dias da semeadura em substrato contaminado com 2,4-D + Picloram. Alta Floresta-MT, 2007. 
Através dos dados obtidos pelo presente trabalho, é possível inferir sobre a importância da utilização de substratos sem contaminação de herbicidas, principalmente aqueles utilizados em larga escala em áreas de pastagens e criações, como o 2,4-D + Picloram, pois, como observado, mesmo em doses reduzidas, o potencial de danos pode ser grande, podendo haver perspectivas na redução na eficiência produtiva do agricultor, caso se utilize de solo contaminado.

Tabela 3. Notas de fitointoxicação de olerícolas cultivadas em substrato contaminado com 2,4-D + Picloram, aos 7 e 14 dias após a semeadura. Alta Floresta-MT, 2007.

\begin{tabular}{|c|c|c|c|c|c|c|}
\hline \multirow{4}{*}{$\begin{array}{c}\text { Doses do } \\
\text { herbicida ( } L \\
\left.\text { ha }^{-1}\right)\end{array}$} & \multicolumn{6}{|c|}{ Culturas } \\
\hline & \multicolumn{2}{|c|}{ Alface } & \multicolumn{2}{|c|}{ Tomate } & \multicolumn{2}{|c|}{ Pepino } \\
\hline & \multicolumn{6}{|c|}{ Dias após a semeadura } \\
\hline & 7 & 14 & 7 & 14 & 7 & 14 \\
\hline 0,00 & $0,0 \mathrm{a}$ & $0,0 \mathrm{a}$ & $0,0 \mathrm{a}$ & $0,0 \mathrm{a}$ & $0,0 \mathrm{a}$ & $0,0 \mathrm{a}$ \\
\hline 0,04 & $0,6 \mathrm{~b}$ & $1,0 \mathrm{~b}$ & $1,3 \mathrm{~b}$ & $1,4 \mathrm{~b}$ & $1,0 \mathrm{~b}$ & $1,0 \mathrm{~b}$ \\
\hline 0,08 & $1,4 \mathrm{c}$ & $2,0 \mathrm{c}$ & $1,4 \mathrm{~b}$ & $1,6 \mathrm{~b}$ & $1,0 \mathrm{~b}$ & $1,0 \mathrm{c}$ \\
\hline 0,12 & $1,9 \mathrm{c}$ & $3,1 \mathrm{~d}$ & $2,6 \mathrm{c}$ & $3,1 \mathrm{c}$ & $1,9 \mathrm{c}$ & $2,5 \mathrm{~d}$ \\
\hline 0,48 & $2,5 \mathrm{~d}$ & $3,9 \mathrm{e}$ & $3,4 \mathrm{~d}$ & $3,5 \mathrm{c}$ & $3,1 \mathrm{~d}$ & $3,1 \mathrm{e}$ \\
\hline 0,96 & $5,0 \mathrm{e}$ & $5,5 \mathrm{f}$ & $4,5 \mathrm{e}$ & $5,0 \mathrm{~d}$ & $4,5 \mathrm{e}$ & $6,0 \mathrm{f}$ \\
\hline C.V. (\%) & \multicolumn{2}{|c|}{20,30} & \multicolumn{2}{|c|}{15,64} & \multicolumn{2}{|c|}{17,40} \\
\hline
\end{tabular}

Médias seguidas de mesma letra nas colunas não diferem entre si pelo teste de Scott \& Knott a 5\% de probabilidade.

\section{Conclusão}

Solos contaminados com 2,4-D + picloram provocaram redução na emergência de plantas de alface, tomate e pepino a partir de doses de $0,08 \mathrm{~L}$ $\mathrm{ha}^{-1}$.

A contaminação de solos com 2,4-D + picloram interferiram no crescimento de plantas de tomate e pepino, havendo redução na altura de plantas a partir de doses de $0,04 \mathrm{~L} \mathrm{ha}^{-1}$.

Ocorreu um aumento na fitointoxicação de plantas de alface, tomate em doses acima de 0,04 L $\mathrm{ha}^{-1}$, sendo crescentes os sintomas, a medida que as doses de contaminação eram aumentadas.

\section{Referências}

ALENCAR, J. A.; LIMA, M. F.; CARVALHO, G. A.; OLIVEIRA, C. M. Descarte de embalagens de agrotóxicos. Ecotoxicologia e Meio Ambiente, Curitiba, v. 8, p. 9-26, jan./dez, 1998.

ALVARENGA, M. I. N.; CONTIJO, R. A. N.; ALVES, H. M. R.; NOGUEIRA, N. D.; NÓBREGA, J. C. A. Destinação segura das embalagens vazias de agrotóxicos. Informe Agropecuário, Belo Horizonte, v. 24, n. 220, p. 7-17, 2003.

BRASIL. Ministerio das Minas e Energia Departamento Nacional da Produção Mineral. Projeto RADAMBRASIL: programa de integração nacional. Rio de Janeiro : DNPM, 1980. v. 20. (Levantamento de Recursos Naturais, 20).

BRASIL. Ministério da Agricultura e Reforma Agrária. Regras para análise de sementes. Brasília: SNDA/ DNDV/CLAV, 1992. 
CESSNA, A. J.; WADDINGTON, J.; BITTMAN, S. Residues of 2,4-D and picloram in aspen poplar and soil after application with a roller. Canadian Journal of Plant Science, Ottawa, v. 69, p. 205-212, 1986.

CONSTANTIN, J.; OLIVEIRA JÚNIOR, R. S.; BRANDÃO FILHO, J. U. T.; CALLEGARI, O.; PAGLIARI, P. H.; ARANTES, J. G. Z. Efeito de subdoses de 2,4-D na produtividade de fumo e suscetibilidade da cultura em função de seu estádio de desenvolvimento. Engenharia Agrícola, Sorocaba, v. 27, n. esp., p. 30-34, 2007.

DEUBER, R. Mecanismos de ação dos herbicidas. In: DEUBER, R. Ciência das plantas infestantes: fundamentos. 2.ed. Jaboticabal: Funep, 2003. p. 304347.

DEUBERT, K. H.; CORTE-REAL, L. Soil residues of picloram and triclopyr after selective foliar application on utility rights-of-way. Journal of Arboriculture, Savoy, v. 12, n. 11, p. 269-272, 1986.

FAGLIARI, J. R.; OLIVEIRA JÚNIOR, R. S.; CONSTANTIN, J.; HOMEM, L. M.; SOARES, R. Efeitos e impacto econômico da aplicação de subdoses de 2,4-D, simulando deriva sobre o tomateiro (Lycopersicon esculentum). In: CONGRESSO BRASILEIRO DA CIÊNCIA DAS PLANTAS DANINHAS, 24., 2004, São Pedro. Resumos... São Pedro: SBCPD, 2004. CDROM.

FILGUEIRA, F. A. R. Novo manual de olericultura: agrotecnologia moderna na produção e comercialização de hortaliças. 2.ed. Viçosa: UFV, 2003.

FREITAS, F. C. L.; FERREIRA, L. R.; SILVA, A. A.; BARBOSA, J.G.; MIRANDA, G. V.; MACHADO, A. F. L. Eficiência do triclopyr no controle de plantas daninhas em gramado (Paspalum notatum). Planta Daninha, Rio de Janeiro, v. 2, n. 1, p. 159-164, 2003.

JOHNSON, W. G.; LAVY, T. L.; GBUR, E. E. Sorption, mobility, and degradation of triclopyr and 2,4-D on four soils. Weed Science, Champaign, v. 43, p. 678-684, 1995.

MISLEVY, P.; MULLAHEY J. J.; MARTIN F. G. Response of tropical soda apple (Solanum viarum) to triclopyr. Soil Crop Science Society of Florida Proceedings, Belle Glade, n. 56, p. 11-13, 1997.

MUllaheY J. J.; CORNELL, J. A.; COLVIN, D. L. Tropical soda apple (Solanum viarum) control. Weed Technology, Champaign, v. 71, n. 3, p. 723-727, 1993.
OLIVEIRA JÚNIOR， R. S.; CONSTANTIN, J.; BRANDÃO FILHO, J. U. T.; CALLEGARI, O.; PAGLIARI, P. H.; CAVALIERI, S. D.; FRAMESQUI, V. P.; CARREIRA, S. A. M.; ROSO, A. C. Efeito de subdoses de 2,4-D na produtividade de uva itália e suscetibilidade da cultura em função de seu estádio de desenvolvimento. Engenharia Agrícola, Sorocaba, v. 27, n. esp., p. 35-40, 2007.

ROMAN, E. R.; BECKIE, H.; VARGAS, L.; HALL, L.; RIZZARDI, M. A.; WOLF, T. M. Como funcionam os herbicidas: da biologia à aplicação. Passo Fundo: Berthier, 2007.

SANTOS, M. V.; FERREIRA, F. A.; FREITAS, F. C. L.; CUSTÓDIO, G. S.; FONSECA, D. M.; FERREIRA, L. R. Ação residual no solo de herbicidas utilizados em pastagens. In: CONGRESSO BRASILEIRO DA CIÊNCIA DAS PLANTAS DANINHAS, 24., 2004, São Pedro. Resumos... São Pedro: SBCPD, 2004. CDROM.

SANTOS, M. V.; FREITAS, F. C. L.; FERREIRA, F. A.; VIANA, R. G.; TUFFI SANTOS, L. D.; FONSECA, D. M. Eficácia e persistência no solo de herbicidas utilizados em pastagem. Planta Daninha, Rio de Janeiro, v. 24, n. 2 , p. 391-398, 2006.

SILVA, A. A.; FERREIRA, F. A.; FERREIRA, L. R. Biologia e controle de plantas daninhas. Viçosa: DFT/ UFV, 2002. CDROM.

SILVA, A. A.; FERREIRA, F. A.; FERREIRA, L. R. Herbicidas: classificação e mecanismos de ação. In: SILVA, A. A.; SILVA, J. F. (Eds.). Tópicos em manejo de plantas daninhas. Viçosa: UFV, 2007. p.83-148.

SOCIEDADE BRASILEIRA DA CIÊNCIA DAS PLANTAS DANINHAS. Procedimentos para instalação, avaliação e análise de experimentos com herbicidas. Londrina: SBCPD, 1995.

THILL, D. Growth regulator herbicides. In: WELLER, S. C.; THILL, D.; BRIDGES, D. C.; VAN SCOYOC, G. E.; GRAVEEL, J. G.; TURCO JÚNIOR., R. F.; GOLDSBROUGH, P.; RUHL, G. E.; HOLT, H. A.; REICHER, Z. J.; WHITFORD, F. (Eds.). Herbicide action course. West Lafayette: Purdue University, 2003. p. $267-275$.

WEBBER, J. B.; MILLER, C. T. Organic chemical movement over and through soil. In: SAWHNEY, B. L.; BROWN, D. (Eds.). Reactions and movement of organic chemicals in soil. Madison: SSSA, 1989. p. 305-334. 